\title{
Planning for Closure — Example from Fäboliden Mine in Sweden
}

\author{
A.G. Bjelkevik SWECO AB, Sweden
}

\begin{abstract}
Fäboliden is a planned new Swedish goldmine, owned by Lappland Goldminers AB. A permit granting commencement of operations was issued in December 2007, but was subsequently appealed by the Swedish Environmental Protection Agency and some stakeholders in January 2008. New Supreme Court negotiations took place in May 2008.
\end{abstract}

Some of the main issues during negotiations, and the reasons that the Swedish Protection Agency appealed the granting of the permit, are related to closure and financial security for remediation works. Other issues during negotiations, and the reasons for appeal by some stakeholders, are related to the operation itself. These latter issues, however, are not dealt with in this paper.

This paper describes design issues, and the design process for this new mine, with a focus on closure. This includes the objectives of the company (Lappland Goldminers AB), requirements of the authorities, and the philosophy regarding mine closure in Sweden. The focus on closure of mining operations, and specifically tailings facilities, has increased during the last decade. Experience and research have not progressed at the same rate, resulting in some issues remaining in a "Catch 22" situation.

Using Fäboliden as an example, this paper summarizes the issues requiring further attention in the field of mine closure and remediation of tailings facilities in order to increase knowledge and experience regarding long-term (more than 1000 years) development of these facilities. One of these issues is the long-term stability of tailings dams. Developments in fields relating to this issue are important for existing and new mines, not just in Sweden, but for the mining industry as a whole, where remediation incorporates water cover or residual high hydraulic gradients within the tailings dams.

\section{Introduction}

The owner of Fäboliden, Lappland Goldminers AB, is a junior gold company with properties in Sweden and Finland, including one mine in operation. A permit granting commencement of operations at Fäboliden was issued in December 2007, but was subsequently appealed in January 2008. The proceedings in the Supreme Environmental Court of Appeals took place in May 2008, two days after which an immediate execution was issued. The final verdict from the Supreme Environmental Court is expected to be issued in September 2008.

Some of the main issues during negotiations, and one of the reasons that the Swedish Environmental Protection Agency appealed the granted permit, were related to closure and financial security for remediation works. Other issues during negotiations, and the reasons for some stakeholders to appeal, are related to the operation itself. These latter issues are however not dealt with in this paper.

This paper discusses the most important design issues for tailings dams, with a focus on closure as well as the process of developing the design of Fäboliden. This includes the objectives of the company (Lappland Goldminers $\mathrm{AB}$ ), requirements of the authorities, and the philosophy regarding closure in Sweden. The focus on closure of mining operations, and specifically of tailings facilities, has increased during the last decade. Experience and research have, however, not progressed at the same rate, resulting in some issues remaining in a "Catch 22" situation. Specific fields of research are therefore discussed.

\section{Definitions}

The most important definition for this paper is that of long-term. In a philosophical context in Sweden, the phrase long-term closure of tailings facilities means permanent or at least to the next glacial period, which will take place in approximately 10,000 years. However, a time period that is practically manageable, and in line with the practice in many other countries, is defined as 1000 years. 
Tailings facility is herein defined as the facility used to store deposited tailings, which includes the dam embankments and the storage itself, as well as the required system/equipment for deposition of tailings. Other terms with the same meaning may be tailings storage facility or tailings management facility, etc.

Other terms that need to be addressed are dam stability, slope stability, surface stability and stability. In this paper dam stability is defined as the physical stability of the tailings dam embankment, i.e. the perimeter wall, with regard to slip surfaces and internal processes, such as internal erosion. Slope stability is the stability of the face of the tailings dam, which is exposed to external erosion, etc. Surface stability is the stability of the surface of the impoundment (i.e. the horizontal surface), and stability is the overall stability of the tailings facility, including all of the others.

\section{Fäboliden Mine}

Fäboliden gold deposit is situated in the centre of the Swedish "Gold Line", $40 \mathrm{~km}$ west of Lycksele in the county of Västerbotten (see Figure 1). The deposit is initially to be mined as an open pit, to a depth of approximately $200 \mathrm{~m}$ over five years. Thereafter, large-scale low cost underground mining may be used. The processing facility for extraction of gold and silver is to be designed to process the Fäboliden ore, as well as ore from similar deposits from the surrounding area. Lappland Goldminers, as well as other companies, are currently investigating and exploring other deposits in the "Gold Line" area (see Figure 1). The likelihood that the Fäboliden processing plant will process ores from several mines is high, which has been taken into account in the design process of the tailings facility, i.e. its storage capacity (Lappland Goldminers AB, 2008).
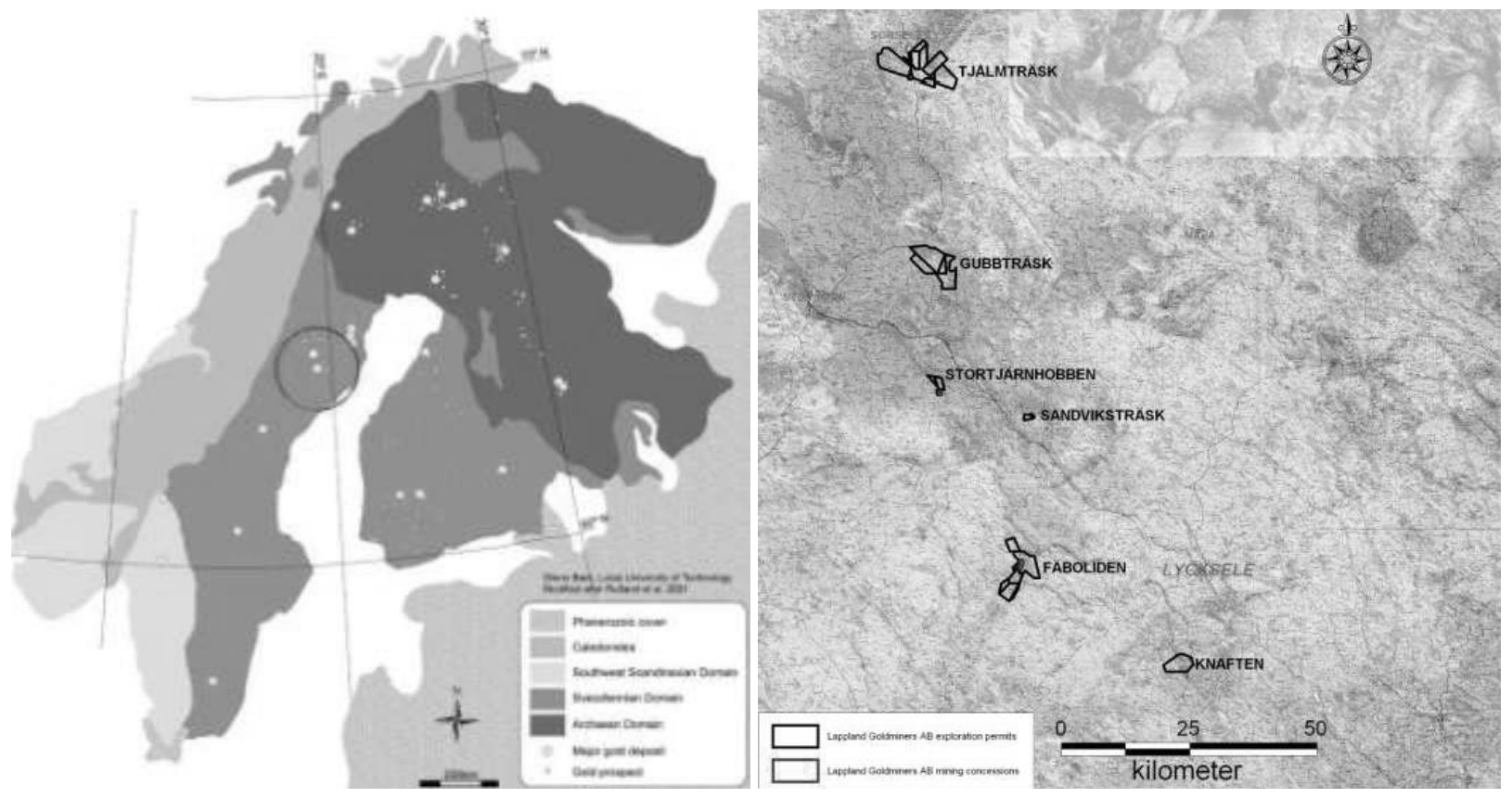

Figure 1 (left) the "Gold Line", marked with a circle, in northern Sweden (Lappland Goldminers $A B, 2008$ ) and (right) location of gold deposits where Lappland Goldminers is carrying out exploration works (Lappland Goldminers AB, 2008)

\section{Fäboliden tailings facility}

\subsection{General design issues}

Generally, a Swedish tailings facility should be designed to be stable until the next glacial period, or more practically for 1000 years (see Section 2). The general goal for closure of tailings facilities containing reactive tailings is to reduce the release levels to be similar to those from the natural environment in the area. This is in principle shown in Figure 2 (ICOLD, 1996) by curve B. Curve A in Figure 2 represents the case where no closure measures are taken. In this case, the release would gradually rise until, at some time in the 
future, the release level would presumably stabilize at a level unacceptable from an environmental point of view. Any tailings facility should therefore be planned, designed, operated and closed to meet the necessary requirements to follow curve $\mathrm{B}$ after closure.

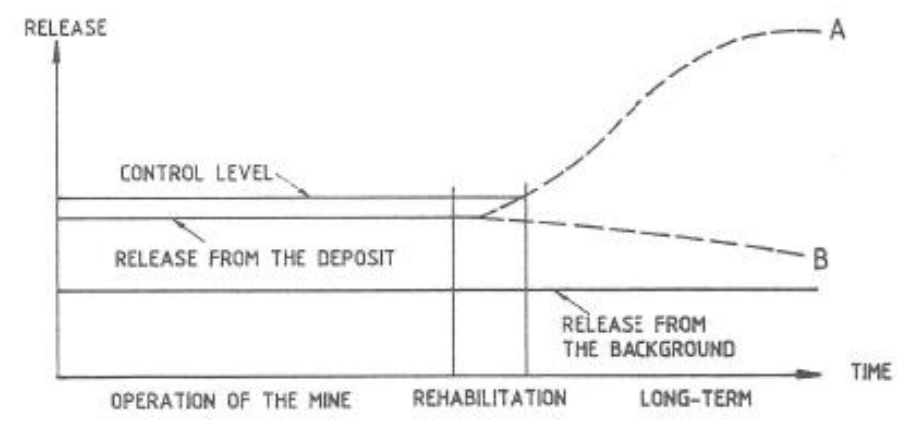

Figure 2 Release levels from a tailings facility with time (ICOLD, 1996)

Taking closure and the long-term aspects of a tailings facility into account during the planning stage does not only include a closure plan, but a design that incorporates a suitable closure method from the start. Closure will therefore affect not just the design, but often also the operation of the tailings facility, as well as related structures. Examples of issues to be considered with regard to closure of a tailings facility include (Bjelkevik, 2005):

\section{- Climate change}

Climate change will certainly have an effect on closure, especially when it comes to the expected magnitudes of extreme events. Climate research is a field of its own and is not addressed in this paper.

- Politics

It is difficult to predict what the world, Europe, or even Sweden will look like 1000 years from now, or whether the borders of countries will change. Looking back 1000 years, one sees a very different picture from today, and situations develop at an even more rapid pace today.

- Social aspects

In many cases, mines have been the reason for a village or town to develop, and, in that case, the ramifications of closing a mine could be severe for the community concerned in respect of jobs, etc., both at the mine and at related supply businesses. In these cases, it might be necessary to enable and support other operations, if possible.

- Land use

Depending on the pre-mining situation activities and the opportunities available after decommissioning, the land may be used for different purposes. In Sweden, the general approach is to turn the mine site back into natural land, for example into forest land or a lake. There are, however, examples of mine sites that have been turned into other uses such as golf courses. Different options for possible alternatives with regard to land use should be considered during the planning process.

- Aesthetics

The meaning of aesthetics in this case is that mining facilities should blend in as much as possible with the surrounding landscape. This is, however, not always easy as blending in is somewhat subjective. One important factor for blending in is that, in many cases, landforms in the surrounding landscape have been or are relatively stable, and if these forms/shapes are copied, the chances of a stable tailings facility are increased.

- History of the facility

While the future operation and closure of the facility cannot be incorporated in the planning process, the closure plan should be updated on a regular basis, and finalized when operations come to an end. At that time, all events, for example failures and incidents, which could have a future effect and/or be of importance to closure, should be taken into account. 


\section{- Environmental aspects}

Environmental aspects includes several aspects such as chemical processes, seepage, the use of natural materials, exhaust pollution from material transport, etc., related to the behavior of the whole tailings facility. This is not discussed further here.

- Economy

Economic aspects are always important. Closure is often associated with large costs, and in this case the closure option that gives the best value for money should be used, taking all aspects into consideration.

\section{- Possibility of re-mining}

Developing countries are rapidly increasing their per capita rate of consumption of metals, and the demand will most likely continue to increase in the long-term. Re-mining of tailings may therefore be profitable in the future, and there are many re-mining operations around the world. Re-mining must, however, not become a reason not to plan for closure or to carry out closure monitoring.

\section{- Dam safety}

All technical aspects that need to be considered with regard to stability of the tailings dams are included in dam safety. These aspects are, for example: long-term dam stability including internal erosion, long-term slope stability, long-term surface stability and extreme events to which the tailings facility may be exposed, as well as slow deterioration processes.

- Material properties

Material properties of deposited tailings and embankment materials may alter over time. Many nongeological construction materials have a lifetime of between fifty and two hundred years, which is insufficient for closure in this case.

\section{- Maintenance and long-term control}

The Swedish philosophy regarding closure is that closure should be maintenance-free and not subject to control requirements. In reality, this may be difficult to achieve for several reasons. However, closure design should aim to achieve such measures. When closure measures are finalized, the mining company has to survey the facility for a minimum period of thirty years, known as the aftercare period. Following this period, the mining company may be allowed to leave the site. No mine has yet, however, reached this point in Sweden. No matter what happens following the after-care period, there will need to be a record that there was a mine in operation at this location, and that some kind of activities cannot be allowed, such as, for example, excavations of the surface or slopes of the remediated tailings facility.

All these issues may not be possible to determine, or foresee, in the long-term perspective, but they need to be addressed, and the best that can be done with the available knowledge should be undertaken. Many of the issues listed above need further research and experience, such as climate change, environmental aspects, dam safety, and changing material properties over time. Other issues, such as land use and aesthetics are very difficult to predict and/or quantify. The best we can do is to take all existing knowledge into account and try to predict the future, or ensure that there are adequate margins to cover unforeseen changes. The focus of this paper is, however, dam safety, which in turn is affected by the other issues, primarily by climate change, the history of the facility, and changing material properties, which will not be dealt with herein.

\subsection{Design requirements by the authorities}

The Swedish authorities (i.e. the Swedish Environmental Protection Agency) have, during the Fäboliden permitting process, raised some requirements that need to be fulfilled with respect to closure and long-term stability of a tailings facility. Four of these requirements are:

- The factor of safety (FS) for dam stability must at all times be at least 1.5. This should include extreme situations under which, for example, the function of any internal filters and/or drains may be neglected.

- The angle of the hydraulic gradient within the dam must at all times be less than half the value of the friction angle in degrees for the actual material to ensure the risk of internal erosion is minimized. 
- There should be an independent audit of the proposed design for the tailings facility.

- Financial security is required for remediation works.

\subsection{Design process for the Fäboliden tailings facility}

\subsubsection{General}

Initially, several alternatives were studied with regard to both the extraction process and the tailings facility. In the following sections the final option chosen for Fäboliden is described and discussed.

\subsubsection{Objectives of Lappland Goldminers}

Lappland Goldminers objectives for the Fäboliden project include:

- A facility with storage capacity sufficient for sixty five million $\mathrm{m}^{3}$, located relatively close to the process plant, with a potential for expansion.

- Cost-efficient design and technology regarding construction, operation and closure.

- Deposition and operation methods shall meet high demands with regard to environmental safety.

- The tailings facility shall be stable in the long-term, and closure measures that can be taken during planning and operation should be taken at those times.

- To contribute to economic and social growth and become one of the major employers within the region.

- The perspective of stakeholders shall remain in focus and possible conflicts of interest minimized.

These objectives of Lappland Goldminers have resulted in some major technical measures being taken, including:

- Separation of the tailings into different environmental components before deposition.

- Treatment of process water before discharge to the environment.

- Naturally sealed foundation under the tailings impoundment.

- Long-term dam stability, with a low hydraulic gradient.

- Landscaping during final operation and closure.

- Local industries and companies engaged to a large extent.

\subsubsection{Design of the tailings facility}

The design process has been based on the properties of the ore, which is a gold deposit with some silver. To extract the gold, cyanide processing has been chosen. As a result, high levels of nitrogen in the process water will become a problem. This prompted a new method within the Swedish mining industry in which biological purification of the process water is used before excess water is discharged. The final decision to use this purification process was based on successful results from a pilot plant test run at an adjacent gold extracting facility. Biological purification is not discussed further in this paper ${ }^{1}$.

The tailings facility in Fäboliden is designed to store the tailings produced from Fäboliden mine and from other future mines in the area. The total storage capacity is to be sixty five million $\mathrm{m}^{3}$, of which approximately $30 \%$ will be utilized to store the tailings from processing ore from the open pit at Fäboliden. The total storage will cover an area of approximately five $\mathrm{km}^{2}$, while $30 \%$ will correspond to approximately three $\mathrm{km}^{2}$. The area of the impoundment will increase with the increasing height of two embankments. Depending on future new mines and the development of the Fäboliden mine, the tailings facility will have

\footnotetext{
${ }^{1}$ Interested parties may address their questions to Mr S. Morling at SWECO Environment AB, Sweden. stig.morling@ sweco.se
} 
the potential to increase the storage capacity to approximately 150 million $\mathrm{m}^{3}$. The current application is, however, for deposition of sixty five million $\mathrm{m}^{3}$ and a construction period of ten years. Thereafter, a new permit will be required.

Tailings deposition will involve the separation of High Risk (HR) tailings and Low Risk (LR) tailings. The purpose of separation is to be able to store the HR tailings in the central parts of the tailings facility surrounded by LR tailings, which then will work as a filter (Figure 3). The environmental properties of the HR and LR tailings are shown in Table 1. The properties of the LR tailings are similar to those of natural material in the area.

Table 1 Results from analysis of HR and LR tailings from test processing of the Fäboliden ore (Ylvén, 2007). Units are mg/kg

\begin{tabular}{lcc|ccc}
\hline Element & HR Tailings & LR Tailings & Compound & HR Tailings & LR Tailings \\
\hline $\mathrm{As}$ & 47500 & 197 & $\mathrm{SiO}_{2}$ & 31.1 & 56 \\
$\mathrm{Cr}$ & 207 & 367 & $\mathrm{Al}_{2} \mathrm{O}_{3}$ & 8.25 & 13.2 \\
$\mathrm{Cu}$ & 1330 & 54.3 & $\mathrm{CaO}$ & 7.26 & 11.1 \\
$\mathrm{Ni}$ & 275 & 17.5 & $\mathrm{Fe}_{2} \mathrm{O}_{3}$ & 21.4 & 5.73 \\
$\mathrm{~Pb}$ & 788 & 43.7 & $\mathrm{MgO}$ & 3.93 & 6.91 \\
$\mathrm{~S}$ & 112000 & 2190 & $\mathrm{~K}_{2} \mathrm{O}$ & 1.1 & 1.86 \\
\hline $\mathrm{Zn}$ & 4810 & 60 & $\mathrm{Na}_{2} \mathrm{O}$ & 1.29 & 1.69 \\
\hline
\end{tabular}

As a result of the properties of the LR tailings, i.e. that the LR tailings are essentially non-reactive, it was suggested that the dam embankments be constructed using the upstream method using LR tailings (see Figure 3), which will also ensure a sufficiently low hydraulic gradient (Figure 4). The proposed dam design includes a starter dam, 8 to $15 \mathrm{~m}$ high, constructed of waste rock, with drainage and filter materials. Spigots will be used for deposition and the coarse tailings will be used for raising the embankment. LR waste rock will be used as erosion protection on the downstream slopes. The beach will be at least one hundred meters long, and the final height of the dam will be approximately $40 \mathrm{~m}$.

Figure 5 shows two different calculations (using SEEP/W) of the hydraulic gradient: a) for normal operating conditions with full filter and drainage function and water at the operational level, and $b$ ) for the long-term case with fully blocked filters and drains and the maximum water level. The filters are assumed to be blocked through internal erosion of fine and coarse tailings. The result of the calculations is that the hydraulic gradient during operation (a) reaches a maximum of approximately 4.8 and with blocked filters and drains reaches a maximum of approximately 8 . 


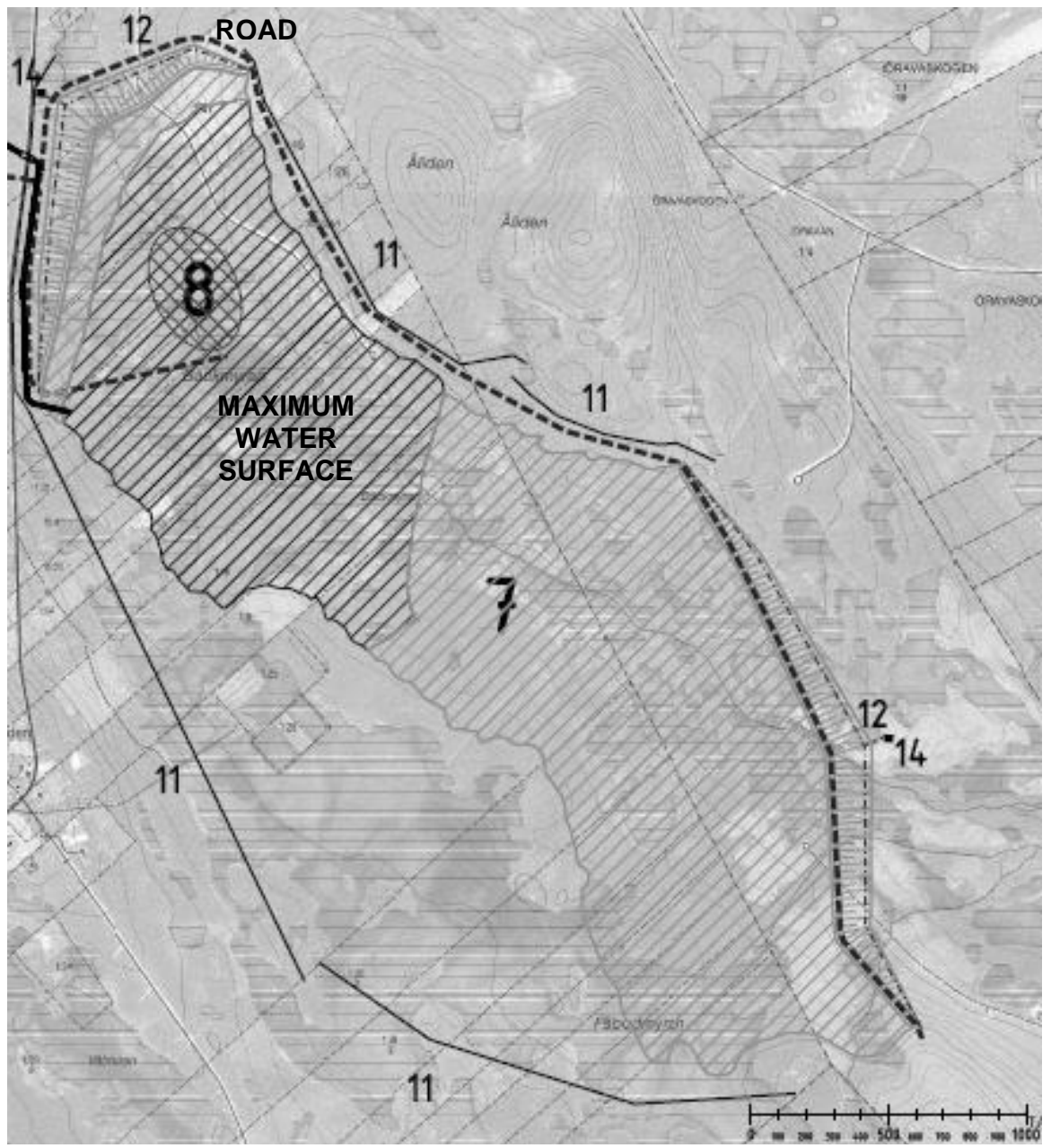

Figure 3 Proposed layout for Fäboliden tailings facility. 7) Deposited LR material, 8) Deposited HR material, 11) Stormwater ditch, 12) Pipe for collection of seepage water, 14) Pump station for seepage water back to impoundment (SWECO, 2007)

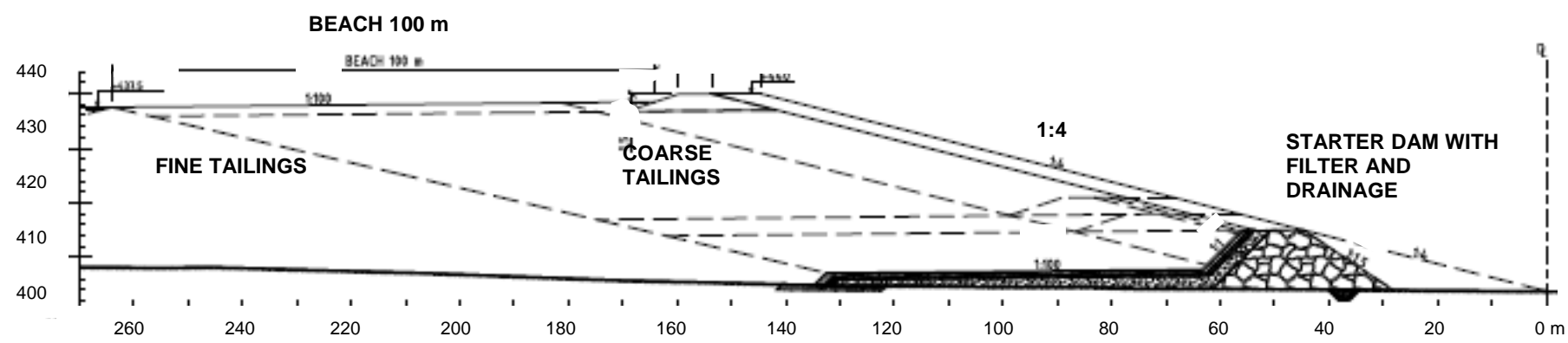

Figure 4 Cross section of proposed upstream dam embankment for Fäboliden tailings facility. The starter dam consists of a toe embankment of waste rock downstream and a layer of sorted waste rock placed as an upstream blanket with a sloping surface of $1(\mathrm{~V}): 100(\mathrm{H})$. On top of the sorted waste rock is a coarse and fine filter (Hifab and SWECO, 2007)

By using tailings and waste rock for dam construction natural resources, such as till, are saved, which is environmentally beneficial.

As a complement to the separation of tailings, the waste rock is to be separated in a similar manner into HR and LR waste rock. HR waste rock will be co-deposited with the HR tailings in the centre of the tailings impoundment (see Figure 3) and the LR waste rock will be deposited in a waste dump next to the open pit. In 
this manner, the HR waste rock will be handled in the same way as the HR tailings, and the LR waste rock will simply require vegetation measures for closure, which in this case is to involve a cover of $0.3 \mathrm{~m}$ of till.

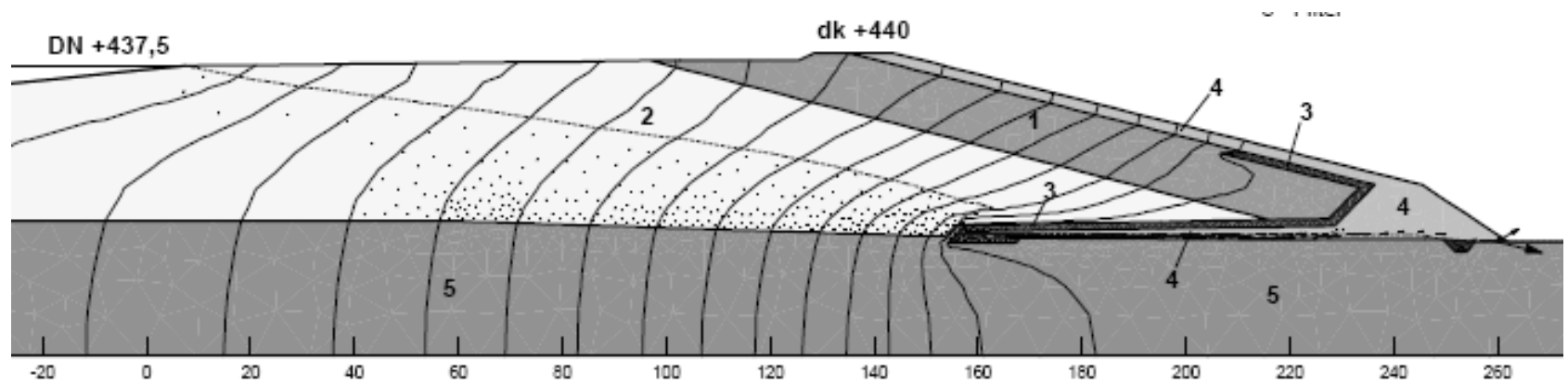

(a) Normal operating conditions

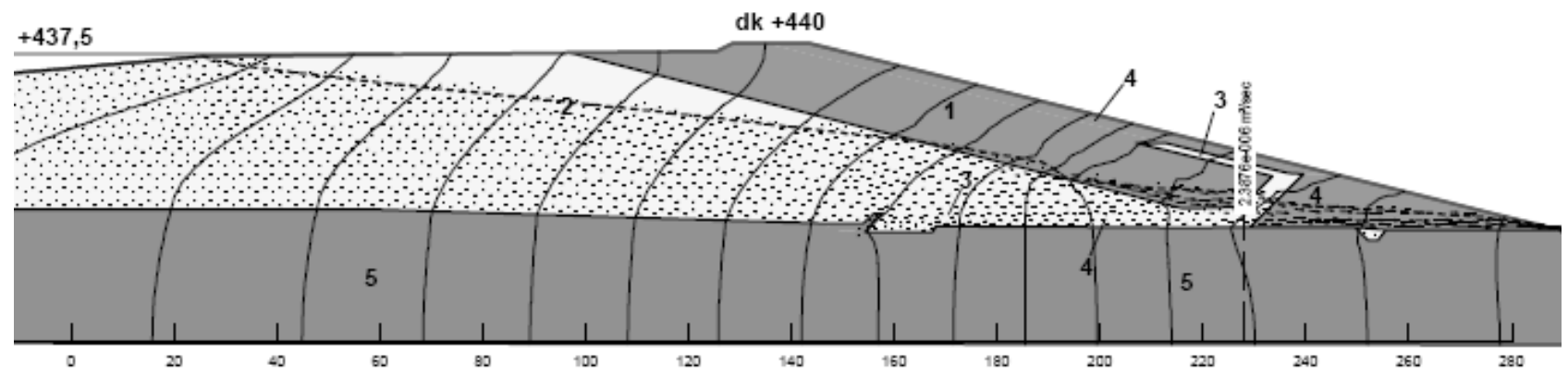

(b) Long-term phase (with blocked filters)

Figure 5 Cross section showing the expected hydraulic gradient a) during normal conditions and b) in the long-term for the proposed upstream dam embankment for Fäboliden tailings facility. 1) Coarse tailings, 2) Fine tailings, 3) Filter, 4) Drainage or erosion protection, 5) Foundation. DN = water level at normal operation, dk = dam crest (Hifab and SWECO, 2007)

A sealed foundation is to be developed by leaving the natural peat layer within the impoundment base. The peat layer, underlain by moraine, will be compressed by the load of the tailings and thereby achieve a low hydraulic conductivity of approximately $10-10 \mathrm{~m} / \mathrm{s}$ (Hifab, 2007).

The closure plan for the Fäboliden tailings facility incorporates both a water/wetland cover and a dry cover. The central section (No. 8 in Figure 3), where the HR material is to be deposited, is to be covered by water to minimize oxidation of the deposited material. The area between the permanent water surface and the dry areas is to become a wetland area. The purpose of the wetland area is to handle the annual fluctuations of precipitation and inflow to the impoundment of the tailings facility. In this way chemical reactions within the HR material will be limited, which together with the long drainage path will result in low release levels (Hifab, 2007).

The HR tailings are not problematic in an environmental sense, since they do not have high levels of sulphur and will therefore not cause problems with dissolved heavy metals. The problem at Fäboliden is arsenic. The available/accessible levels of arsenic will, however, be low given the proposed deposition and closure methods (Hifab, 2008).

The dry areas of the impoundment (comprising LR tailings) will be covered by till and vegetated. The primary goal is to blend the tailings facility in with the surrounding landscape. Trees and bushes will therefore be used to reduce the wind and to create shelter for animals. Open areas are planned such as a sandy moor, vegetated with reindeer lichen (see Figure 6 for an overview of the closed tailings facility). 


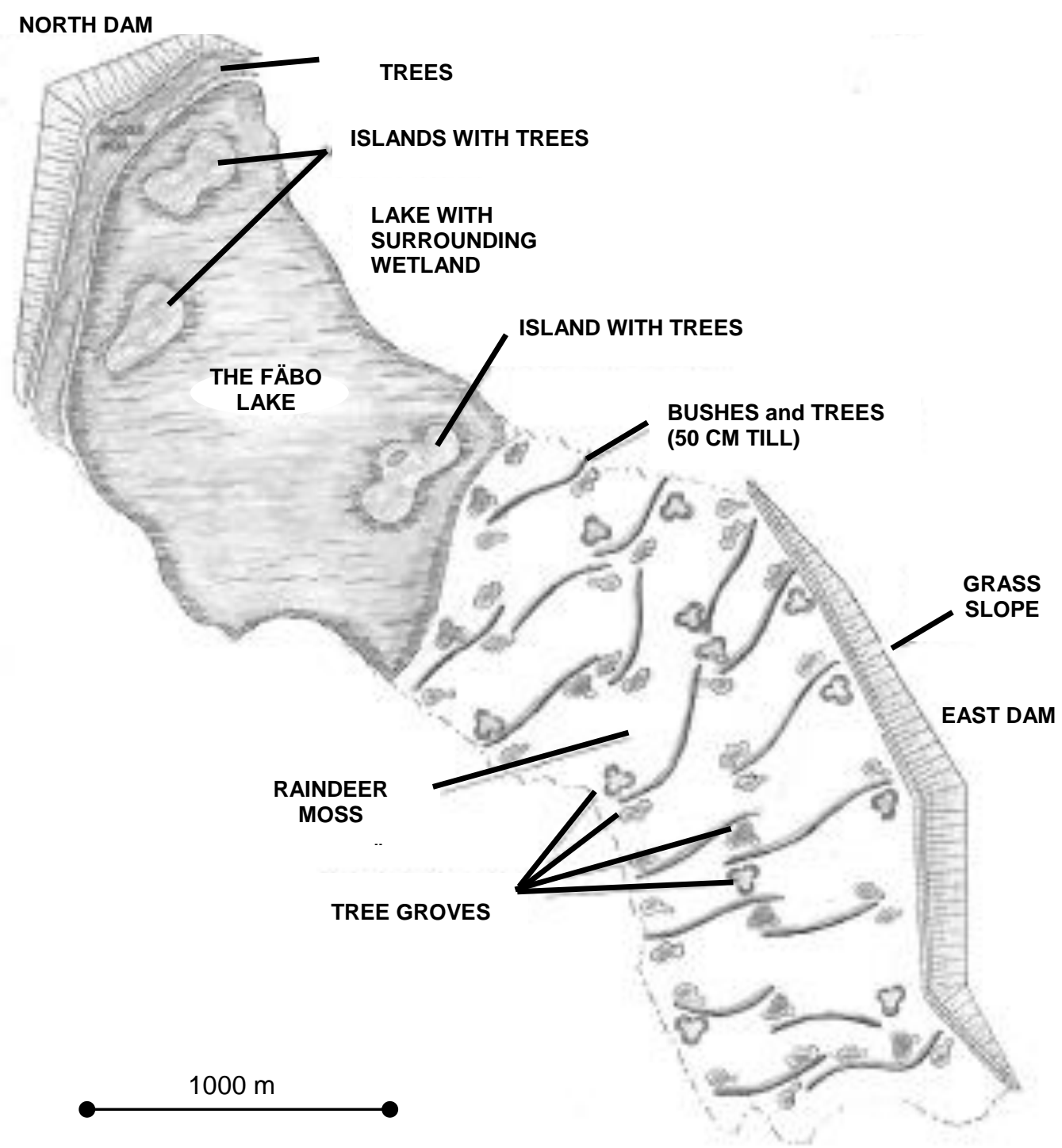

Figure 6 Proposed outlines for closure of Fäboliden tailings facility (SWECO, 2007)

In Sweden financial security for closure will have to be provided in advance (Department of Environment, 1998). If the closure plan can show the actual closure costs at any given time, and if the financial security is guaranteed to be larger than the costs, the security may be refunded progressively. For Fäboliden, financial security will be provided every three months according to the actual closure costs at the time. To illustrate this, a diagram has been developed (see Figure 7). The arrows in Figure 7 illustrate how the diagram is to be used. Following the capital letters anti-clockwise gives the closure cost at a given time indicating a closure cost of approximately 31 MSEK (1 SEK=US\$ 0.16) after five years of operation. Following the arrows "a" and " $b$ " clockwise gives the financial security to be provided at a given time based on the proposed production rate, indicating a financial security is approximately 33 MSEK after five years of operation. If closure measures are undertaken during operation, the financial security may be decreased accordingly. 


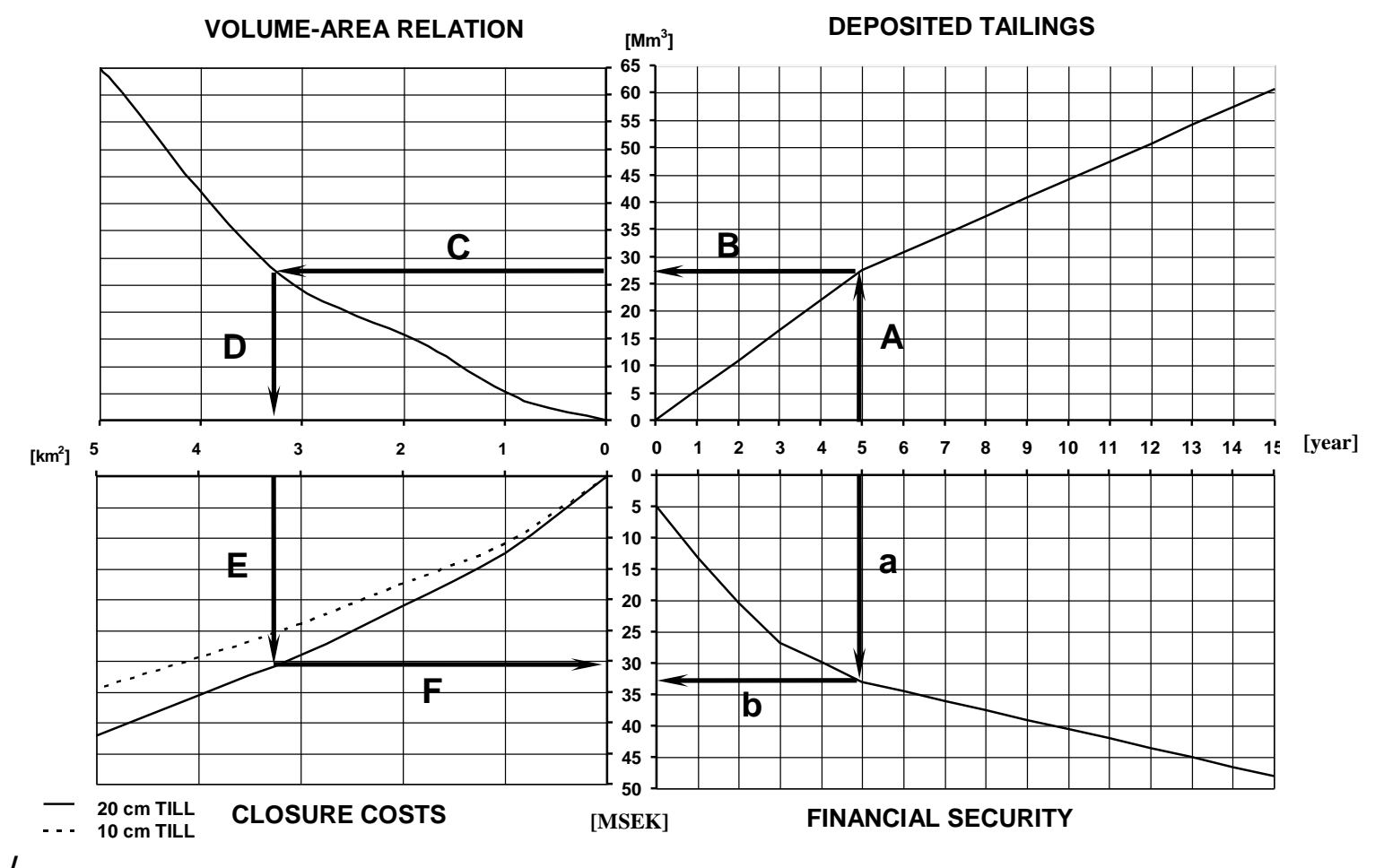

Figure 7 Diagram showing current closure cost at any time and corresponding financial security granted at any time. The arrows A, B, C, D, E, F and a, b, shows an example of the costs after five years of operation, which result in approximately 31 MSEK in closure costs and approximately 33 MSEK for financial security (SWECO, 2007)

\subsection{Issues requiring further attention}

In going through the process of applying for a permit for a new mining operation, or renewing a permit for an existing operation, the parties involved have to take decisions without complete information, knowledge and/or experience. The main question with regards to dam safety is the long-term stability of the dam embankment. Without stable structures surrounding the impoundment, all other measures taken are wasted. Physical stability of tailings dam embankments includes stability against the following (Bjelkevik, 2005):

- Slope failure, including settlements etc.

- Extreme events (seismic and climatic).

- Slow deterioration processes.

There are several questions that are not possible to answer in relation to these three points, including:

- Is it possible to predict the process of internal erosion within the embankment in the long-term?

- Can climate change and seismic events be adequately allowed for?

- Can the effects of weathering and frost and ice forces on the material be adequately allowed for? This may change material parameters in the long-term.

- How will water and wind erosion affect the external face of the tailings facility in the long-term?

- Is it possible to predict the effects of intrusion by future vegetation and/or animals?

These questions require further attention, development and research. For example, if it is not possible to predict the process of internal erosion, it is impossible to design a long-term stable dam, and therefore impossible to present an acceptable closure plan. Without an acceptable closure plan it is impossible to obtain a permit for operation, and the operation is then stuck in a "Catch 22 " situation. 


\section{Discussion}

The legislation in Sweden is complex, and the permit process is time-consuming. Environmental permits are granted via an environmental court system. The application process for Fäboliden started in 2002, and an application was finalized and submitted at the beginning of 2006. The process should be finalized in September 2008, which would mean that it has taken approximately six years, which is similar to other mining application processes (six to seven years) in Sweden. Any permit granted to Fäboliden in September 2008 may, however, be once more appealed.

The requirements defined for Fäboliden by the authorities (see Section 4.1), are more or less fulfilled. Requirement Number 1, regarding the factor of safety is achieved in all cases except one, which is the extreme earthquake. Sweden is a country with low seismic activity. Historically, the most severe seismic activities are related to the last glacial period and the subsequent land rise that occurred thousands of years ago. More recent seismic activities have reached a magnitude of approximately 6 on the Richter scale. The seismic analysis for Fäboliden has assumed full liquefaction of all saturated tailings, without looking at the occurrence probability. This will, however, be examined during detailed design. The extreme seismic event is also not assumed to be a repetitive event. Taking all of these factors into account, a factor of safety of 1.1 is judged to be sufficient at this stage.

Requirement Number 2, regarding the hydraulic gradient, is fulfilled according to the calculations performed. This is, however, true if the material properties are correct, which they are believed to be, as they are assumed to be conservative.

Requirement Number 3, regarding an independent audit, has not at this stage been fulfilled even, though international expertise has been obtained during the design process. An independent audit is, however, meant to take place two to three years after operation starts.

Requirement Number 4, regarding financial security, is fulfilled, as the financial security larger than the actual remediation costs at any given time will be provided.

Of all the topics needing further research, the issue of internal erosion has gained most focus in Sweden. There are ongoing research projects both within the mining industry and the hydro-power industry. Internal erosion is strongly dependent on the hydraulic gradient and the second requirement of the Swedish authorities (under 4.3) is intended to ensure internal erosion will not happen in the long-term. The requirement of the authorities is, however, not scientifically justified, but is derived from an equation used for homogenous slopes of friction material with an infinite length and, in which the phreatic surface is parallel to and at the face of the lower part of the slope (Lamb and Whitman, 1979). Existing filter criteria are empirical and have been revised due to deficiencies experienced at existing dams built during the 1960s and 1970s according to these requirements. On this basis, it is clear that the process of internal erosion is not completely understood. The goal of Swedish research is to try to understand this process, in order to be able to design long-term stable dams where internal erosion is believed to be critical.

Climate change and seismic events are topics of ongoing research, for which data are now collected in order to gain more experience. This will help the process of designing long-term stable structures including tailings facilities. The effects of weathering and change in material properties on materials in the long-term are difficult to predict, and experience and research in this field is limited within Sweden. They are not judged to be as important as internal erosion. This also applies to the effects of the intrusion of vegetation and animals.

Long-term experience based on existing projects is relatively difficult to obtain, as no mine in Sweden has progressed beyond the after-care period. There are, however, several remediated tailings facilities within Sweden for which the after-care period has started, from which experience can be obtained. External erosion processes are another field where further research is necessary. External erosion cannot be avoided in the long-term, but the question remains as to how erosion can be minimized (McPhail, 2006). One approach is to study similar ancient or natural formations that have been exposed to erosion forces over long time periods and try to copy them. 


\section{Conclusion}

Requirements for closure of tailings facilities are becoming better defined with each finalized application process, but actual closure experience remains limited. The application process is, however, still too long in Sweden to create sustainable and sound criteria for the mining industry within the country. Most Swedish mining companies are today committed to doing a good job, not just with regard to their own business, but with regard to the society and the environment as well, which includes closure. Fäboliden is an example of a small mining company that is taking the application process seriously and has devoted considerable resources to the project.

In order to simplify and shorten the application process, as well as support the increase in knowledge and experience regarding long-term issues, the industry and the authorities need to co-operate. Developments within Sweden are going in the right direction with regard to closure of tailings facilities, but the progress could be improved by better understanding and co-operation by all parties involved. There is much research to be done as well as collection and analyses of data from existing facilities, and resources are needed to be able to do this.

\section{Acknowledgements}

This paper is a brief synthesis of the work carried out by a large project group and is the impression and thoughts of the author of this paper. The project group included Lappland Goldminers $\mathrm{AB}$ (the project owner) and two consultant companies; Envipro Miljöteknik AB, Hifab and SWECO AB. For the development and improvement of this paper a number of people have contributed: Karl-Åke Johansson and Torbjörn Ylvén (Lappland Goldminers AB), Prof. Sven Knutsson (Luleå Technical University, LTU), Erik Carlsson (Envipro Miljöteknik AB, Hifab) and Sarah Meck Svärd (SWECO AB).

\section{References}

Bjelkevik, A. (2005) Stability of Tailings Dams: Focus on water cover closure, Licentiate thesis, Luleå university of Technology, Sweden, (http://epubl.ltu.se/1402-1528/2005/index.shtml June 2008).

Department of Environment (1998) Miljöbalk (1998:808), SFS-nummer 1998:808, 16 kapitlet 3§ Lag (2007:661), SFSnummer 2007, $661 \mathrm{p}$.

Hifab (2007) Material for presentation at court negotiations developed by Erik Carlsson, Envipro Miljöteknik AB, Hifab (Project No. 311834/311078).

Hifab (2008) Material for presentation at court negotiations developed by Erik Carlsson, Envipro Miljöteknik AB, Hifab (Project No. 311834/311078).

Hifab and SWECO (2007) Komplettering till ansökan om tillstånd enligt miljöbalken till gruvetablering vid Fäboliden, March 2007, Produced in joint venture by Envipro Miljöteknik AB, Hifab (Project No. 311834/311078) and SWECO AB (Project No. 1643056) - in Swedish.

ICOLD (1996) Tailings Dams and Environment, Review and recommendations, Bulletin 103, International Commission on Large Dams.

Lamb, T.W. and Whitman, R.V. (1979) Soil Engineering, John Wiley.

Lappland Goldminers AB (2008) Fäboliden Gold Project - Mine and Process Plant, Feasibility Study, April 2008, www.lapplandgoldminers.se (June 2008).

McPhail, G. (2006) Erosion Control, How practical is it -Really? Metago Environmental Engineers.

SWECO (2007) Material for presentation at court negotiations developed by SWECO Infrastructure, Dams and Hydropower, Project No. 1643056.

Ylvén, T. (2007) Materialkarakterisering, förslag till separering av restprodukter, klassificering av gråberg och anrikningssand, Torbjörn Ylvén, Lappland Goldminers AB. Lycksele rev. 2007-03-05, in Swedish. 